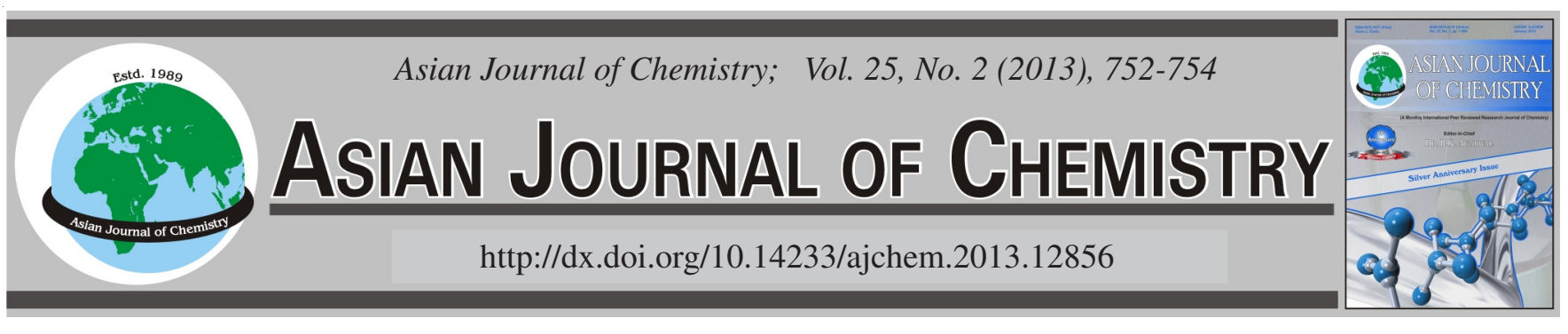

\title{
Determination of Rare Earth Elements in Orchards Soil by Inductively Coupled Plasma-Atomic Emission Spectroscopy
}

\author{
Jun Xue, Lin-Sheng Zhong, Yu-Lan Fan and Xun Li*
}

Research Center of Navel Orange Engineering and Technology-Jiangxi, Gannan Normal University, Ganzhou 341000, P.R. China

*Corresponding author: Fax: +86 797 8393536; Tel: +86 797 8393670; E-mail: lixungnnu@163.com

\begin{abstract}
To investigate spectral interference of $\mathrm{La}, \mathrm{Ce}, \mathrm{Nd}, \mathrm{Sm}, \mathrm{Eu}, \mathrm{Gd}, \mathrm{Tb}, \mathrm{Yb}, \mathrm{Lu}$ and $\mathrm{Y}$ when detecting by inductively coupled plasma-atomic emission spectroscopy (ICP-AES), different types of soils were digested with a mixture of $\mathrm{HF}+\mathrm{HNO}_{3}+\mathrm{HCl}$ by microwave digestion instrument and precipitated twice to remove most of the matrix elements. The results showed a good method with high sensitivity, strong antiinterference ability to determine these elements simultaneously. The results to detect the soil standard reference materials (GSS-4, GSS-5) showed that measured values are all in range the standard value allowed and consistent with the standard value, indicating that the

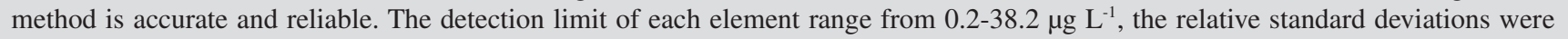
between 0.8 and $3.2 \%$. This method has been successfully applied to determine the content of rare earth elements in soil samples from orchards in southern Jiangxi and the distribution of rare earth elements in the different types of soil were explored.
\end{abstract}

Key Words: ICP-AES, Microwave digestion, Soil, Rare earth element.

\section{INTRODUCTION}

Rare earth elements (REEs) are important nutrient for plant growth and development, rare earth elements can promote plant growth and development, increase fruit production, improve fruit quality and enhance plant disease resistance. Application of rare earth elements in agriculture has been more and more wide after development of decades ${ }^{1}$. Gannan area of Jiangxi province riches in leaching type of rare earth ore, that is ion-adsorption type of rare-earth ore, where the state of rare earth elements are easily absorbed by plants ${ }^{2}$. Gannan is also an important production base of navel orange, which is famous for high quality due to the unique soil conditions, navel orange fruit is orange-red, large, peel thin and the juice rich, sweet and fragrant. Therefore, the study of soil rare earth element contents in Gannan navel orange orchard is important for the Gannan navel orange production. To solve this problem, the methods to determine rare earth elements are particularly important.

Today the main methods of determination of rare earth elements in soil are spectrophotometry, atomic absorption and atomic fluorescence spectrometry, neutron activation analysis, electrochemical analysis, mass spectrometry, X-ray fluorescence spectrometry, plasma emission spectroscopy, ICP-MS etc. $^{3-8}$, in which ICP-MS has advantages of high sensitivity and high accuracy, but its cost is expensive. The ICP-AES method is one of the most popular methods to determine rare earth element because of low detection limit, good precision, linear range and multi-element determination and lower cost etc. ${ }^{9,10}$. In this paper, $\mathrm{La}, \mathrm{Ce}, \mathrm{Nd}, \mathrm{Sm}, \mathrm{Eu}, \mathrm{Gd}, \mathrm{Tb}, \mathrm{Yb}, \mathrm{Lu}$ and $\mathrm{Y}$ in soil were determined by inductively coupled plasma emission spectrometry with microwave digestion and precipitation twice.

\section{EXPERIMENTAL}

Prodigy XP full spectrum inductively coupled plasma atomic emission spectrometry (ICP-AES, Leeman company of USA), Self-excited high-frequency generator, high-resolution echelle, resolution $0.009 \mathrm{~nm}(200 \mathrm{~nm})$, Vertical-Horizontal dual observation system, CCD detector solid; Multiwave 3000 microwave digestion instrument (Anton Paar Company, Austria); Synergy UV Ultra-pure water (Millipore Corporation, USA); LabTech EG20A Electric hot plate (Beijing LabTech Instrument Co. Ltd., China); High-speed universal grinder (Tianjin Test Instrument Co. Ltd., China).

Reagents and standard solutions: Soil reference material (GSS-4, GSS-5) were bought from Institute of geophysical and geochemical of Geology and Mineral Resources Ministry; Nitric acid (excellent grade pure), hydrochloric acid (excellent grade pure), hydrofluoric acid, sodium hydroxide, triethanolamine, magnesium chloride, ammonium chloride, ammonia were all analytical grade; water is processed by Millipore 
TABLE-1

ANALYTICAL WAVELENGTHS AND DETECTION LIMITS OF RARE EARTH ELEMENTS BY ICP-AES

\begin{tabular}{ccc|ccc}
\hline Elements & Wavelength $(\mathrm{nm})$ & Detection limits $\left(\mu \mathrm{g} \mathrm{L}{ }^{-1}\right)$ & Elements & Wavelength $(\mathrm{nm})$ & Detection limits $\left.(\mu \mathrm{g} \mathrm{L})^{-1}\right)$ \\
\hline $\mathrm{La}$ & 333.749 & 2.4 & $\mathrm{Gd}$ & 376.839 & 5.6 \\
$\mathrm{Ce}$ & 413.765 & 14.5 & $\mathrm{~Tb}$ & 370.286 & 7.1 \\
$\mathrm{Nd}$ & 378.425 & 38.2 & $\mathrm{Yb}$ & 328.937 & 0.2 \\
$\mathrm{Sm}$ & 359.260 & 6.8 & $\mathrm{Lu}$ & 261.542 & 0.2 \\
$\mathrm{Eu}$ & 381.967 & 0.6 & $\mathrm{Y}$ & 360.073 & 0.5 \\
\hline
\end{tabular}

ultrapure water instrument; glass apparatus were all soaked by $10 \% \mathrm{HNO}_{3}$ for $24 \mathrm{~h}$.

Standard stock solution: multi-element standard solution of rare earth (Analysis and Testing Center of non-ferrous metals and electronic materials) (GSB 04-1789-2004), concentration is $100 \mu \mathrm{g} \mathrm{mL}$.

Sample collection and preparation: A $40 \mathrm{~cm}$ deep soil profile was dug at sampling point in orchards, sampling $c a .200$ $\mathrm{g}$ soil in profile evenly distributed between $5-35 \mathrm{~cm}$ below the surface of the soil layer, excluding large roots and gravel and other debris, 10-15 soil samples collected were mixed, to take soil samples of $c a .500 \mathrm{~g}$ and crushed in the high-speed grinder with stainless steel, back into the sample bag.

Sample treatment: Weigh accurately about $0.4 \mathrm{~g}$ the prepared soil samples and put into the Teflon reaction tank, add the mixed acid $\left(5 \mathrm{~mL} \mathrm{HNO}_{3}+2 \mathrm{~mL} \mathrm{HCl}+3 \mathrm{~mL} \mathrm{HF}\right)$ in the tank, digest in microwave digestion instrument, cool, transfer to Teflon crucible to catch acid on the electric board until nearly dry; dissolve $c a .4 \mathrm{~g}$ sodium hydroxide into the crucible containing about $30 \mathrm{~mL}$ deionized water, stir, then transferred to aqueous solution containing $10 \mathrm{~mL}$ triethanolamine (1:1) beaker, washed crucible with $60 \mathrm{~mL}$ boiling water repeatedly, the wash solution was transferred into the beaker together. Adding $10 \mathrm{mg}$ magnesium chloride solution, boiling, cooling, filtration, washed precipitate with $2 \%$ sodium hydroxide solution, discard the filtrate. Wash the precipitate into the original beaker with hydrochloric acid (1:1), add $3 \mathrm{~g}$ of ammonium chloride, $100 \mathrm{~mL}$ deionized water, ammonia $20 \mathrm{~mL}$, boil for a second precipitation. Cooling, filtration, washed precipitate with $2 \%$ ammonia-ammonium chloride solution, discard the filtrate and then dissolve precipitate into hot $2 \mathrm{~mol} \mathrm{~L}^{-1}$ hydrochloric acid, washed, concentrated, the volume to $10 \mathrm{~mL}$ flask. At the same time make a blank experiment. The samples were measured in the selected working conditions.

Instrument operating conditions: The optimum operating conditions were input power $1.1 \mathrm{~kW}$, nebulizer pressure $0.2 \mathrm{MPa}$, the cooling air flow $18 \mathrm{~L} \mathrm{~min}^{-1}$, auxiliary gas flow $0.3 \mathrm{~L} \mathrm{~min}^{-1}$, the sampling amount of test solution $1.4 \mathrm{~mL} \mathrm{~min}^{-1}$, high purging and purging $1 \mathrm{~h}$ before the experiment, horizontal observation and integration time $20 \mathrm{~s}$.

\section{RESULTS AND DISCUSSION}

Wavelength interference and selection for the determination of rare earth elements: Each element has several characteristic lines which can interfered with each other when there are many elements ${ }^{11-13}$, usually characteristic lines with high sensitivity and little interference are selected to measure, the selected wavelength of rare earth elements of this study were showed in Table-1. The results showed that La and Sm,
Gd spectrum peaks have interfere on the right; spectrum lines of $\mathrm{Ce}, \mathrm{Nd}, \mathrm{Yb}, \mathrm{Y}$ have no interference; Tb has a peak spectral interference on the left; Eu and Lu have a slope-type interference on the right. Background correction are used right and left background subtraction to correct except La, Sm and Gd only left calibration.

Impacts of acidity on the test: $0.5,1.0,1.5,2.0,3.0 \mathrm{~mol}$ $\mathrm{L}^{-1}$ hydrochloric acid were taken to make a series of concentration of standard solution and detected at the above working conditions. The results showed that when the concentration of hydrochloric acid within 1-3 $\mathrm{mol} \mathrm{L}^{-1}$ the emission spectra intensity of rare earth elements is essentially the same and strong. Therefore, this test selected $2.0 \mathrm{~mol} \mathrm{~L}^{-1}$ hydrochloric acid as the medium.

Analytical figures of merit: Using the optimized conditions and procedure described above, the sensitivity was evaluated for the determination of rare earth elements by ICPAES. The standard stock solution were prepared into $0,0.1$, 1.0 and $5.0 \mathrm{~g} \mathrm{~mL}^{-1}$ of multi-element standard solution of rare earth with $2 \mathrm{~mol} \mathrm{~L}^{-1}$ hydrochloric acid concentrations. The linear correlation coefficients were all between 0.9999-1.000, the favorable correlation showed evidence for the reliability of the proposed method. The detection limits based on three times the standard deviation of 11 measurements of the blank and the slope of the calibration curves, were in the rang of 0.2-38.2 $\mu \mathrm{g} \mathrm{L}^{-1}$ for rare earth elements (Table-1).

Accuracy of the method: The accuracy of the method was evaluated by analyzing soil reference material (GSS-4 and GSS-5). The results showed that measured values are all in range the standard value allowed and consistent with the standard value, indicating that the method is accurate and reliable (Table-2).

TABLE-2

DETERMINATION RESULTS OF RARE EARTH ELEMENTS IN GSS-4 AND GSS-5 $(\mathrm{n}=5)$

\begin{tabular}{ccc|cc}
\hline \multirow{2}{*}{ Element } & \multicolumn{2}{c|}{ GSS-4 $\left(\mu \mathrm{g} \mathrm{g}^{-1}\right)$} & \multicolumn{2}{c}{ GSS-5 $\left(\mu \mathrm{g} \mathrm{g}^{-1}\right)$} \\
\cline { 2 - 5 } & $\begin{array}{c}\text { Measured } \\
\text { values }\end{array}$ & $\begin{array}{c}\text { Standard } \\
\text { value }\end{array}$ & $\begin{array}{c}\text { Measured } \\
\text { values }\end{array}$ & $\begin{array}{c}\text { Standard } \\
\text { value }\end{array}$ \\
\hline $\mathrm{La}$ & 50.01 & $53 \pm 4$ & 35.33 & $36 \pm 4$ \\
$\mathrm{Ce}$ & 141.23 & $136 \pm 11$ & 99.56 & $91 \pm 10$ \\
$\mathrm{Nd}$ & 25.63 & $27 \pm 2$ & 23.55 & $24 \pm 2$ \\
$\mathrm{Sm}$ & 4.22 & $4.4 \pm 0.4$ & 4.12 & $4.0 \pm 0.4$ \\
$\mathrm{Eu}$ & 0.78 & $0.85 \pm 0.07$ & 0.79 & $0.82 \pm 0.04$ \\
$\mathrm{Gd}$ & 4.32 & $4.7 \pm 0.5$ & 3.22 & $3.5 \pm 0.3$ \\
$\mathrm{~Tb}$ & 1.01 & $0.94 \pm 0.09$ & 0.77 & $0.7 \pm 0.1$ \\
$\mathrm{Yb}$ & 4.22 & $4.8 \pm 0.6$ & 2.40 & $2.8 \pm 0.4$ \\
$\mathrm{Lu}$ & 0.78 & $0.75 \pm 0.06$ & 0.43 & $0.42 \pm 0.05$ \\
$\mathrm{Y}$ & 33.13 & $39 \pm 6$ & 18.11 & $21 \pm 3$ \\
\hline
\end{tabular}

Sample analysis: Different soil types from different orchard samples were sampled for analysis, the results are 
TABLE-3

DETERMINATION RESULTS OF RARE EARTH ELEMENTS IN SOIL SAMPLE BY ICP-AES

\begin{tabular}{|c|c|c|c|c|c|c|c|c|}
\hline \multirow{2}{*}{ Element } & \multicolumn{2}{|c|}{ Yellow soil } & \multicolumn{2}{|c|}{ Red soil } & \multicolumn{2}{|c|}{ Paddy soil } & \multicolumn{2}{|c|}{ Purple soil } \\
\hline & Mean $\left(\mu g^{-1}\right)$ & RSD (\%) & $\operatorname{Mean}\left(\mu \mathrm{g} \mathrm{g}^{-1}\right)$ & RSD (\%) & Mean $\left(\mu g^{-1}\right)$ & RSD (\%) & Mean $\left(\mu \mathrm{g} \mathrm{g}^{-1}\right)$ & $\mathrm{RSD}(\%)$ \\
\hline $\mathrm{La}$ & 13.25 & 1.1 & 30.95 & 1.7 & 41.63 & 2.1 & 39.41 & 1.1 \\
\hline $\mathrm{Ce}$ & 69.09 & 0.9 & 135.93 & 0.8 & 149.54 & 1.5 & 114.87 & 1.3 \\
\hline $\mathrm{Nd}$ & 16.85 & 1.8 & 26.92 & 2.1 & 40.13 & 1.4 & 39.77 & 1.8 \\
\hline $\mathrm{Sm}$ & 3.354 & 2.2 & 6.53 & 1.7 & 9.05 & 2.3 & 8.36 & 2.1 \\
\hline $\mathrm{Eu}$ & 0.30 & 2.8 & 0.69 & 3.2 & 0.76 & 2.9 & 1.136 & 1.2 \\
\hline Gd & 1.47 & 2.6 & 3.79 & 2.1 & 5.12 & 2.2 & 3.34 & 1.4 \\
\hline $\mathrm{Tb}$ & 0.74 & 2.5 & 2.51 & 2.1 & 3.93 & 1.6 & 2.76 & 1.6 \\
\hline $\mathrm{Yb}$ & 1.40 & 1.9 & 2.36 & 2.7 & 0.49 & 1.8 & 1.34 & 2.1 \\
\hline $\mathrm{Lu}$ & 0.46 & 3.1 & 0.62 & 2.0 & 0.32 & 2.4 & 0.46 & 2.5 \\
\hline $\mathrm{Y}$ & 11.15 & 1.3 & 22.76 & 1.6 & 13.99 & 1.0 & 16.23 & 2.0 \\
\hline
\end{tabular}

shown in Table-3. The results showed that the total concentration and a single type of rare earth element in orchard soil both conform following rule: red soil $>$ paddy soil $>$ purple soil $>$ yellow soil. The rare earth element contents in different types of soil are different, which is mainly related with the soil parent materials, the formation of different types of soil are the combined result of rock weathering and process of soil formation factors (parent material, climate, topography and biological) in a long time and the parent material is the main source of trace elements, higher level of rare earth is the typical feature of red soil from the South of Jiangxi in China.

\section{ACKNOWLEDGEMENTS}

The project was supported by the National Natural Science Foundation of China (No. 50968002) and the Foundation of Education Committee of Jiangxi province (No.GJJ09580).

\section{REFERENCES}

1. G. Tyler, Plant Soil, 267, 191 (2004).

2. C. Rohana, B.D. Chandrasekara and J.T. Heinz, Paddy Water Environ. 2, 163 (2004).
3. S.B. Sawin and T.V. Petrva, Talanta, 19, 1437 (1972).

4. P.J. Potts, O.W. Thorpe and J.S. Watson, Chem. Geol., 34, 331 (1981).

5. M.F. Thirlwall, Chem. Geol., 35, 155 (1982).

6. J. Rajendran, P.K. Thampi and G. Balasubramanian, Anal. Lett., 39, 2297 (2006).

7. P. Zuzaan, N. Gansukh and D. Bolortuya, X-Ray Spectrom., 39, 52 (2010).

8. D.J. Cai and Y.K. Rui, Asian J. Chem., 23, 2237 (2011).

9. X.D. Cao, M. Yin, X.R. Wang and G.W. Zhao, Chin. J. Anal. Chem., 27, 679 (1999).

10. Y.Y. Xu, H. Wang, G.X. Wang, C. Wu and J.F. Zhou, Appl. Spectros., 64, 543 (2010).

11. S. Gu, H. Ying, Z.G. Zhang, Z.X. Zhuang, P.Y. Yang, X.R. Wang, B.L. Huang and B. Li, Spectrochim. Acta B, 52, 1567 (1997).

12. I. Kolibarska, S. Velichkov and N. Daskalova, Spectrochim. Acta B, 63, 603 (2008).

13. S. Velichkov, E. Kostadinova and N. Daskalova, Spectrochim. Acta B, 53, 1863 (1998). 